\title{
Marshall Klaus: the impact of a pioneer in neonatology
}

\author{
Avroy A. Fanaroff ${ }^{1}$ and Richard J. Martin ${ }^{2}$
}

$E^{-10}$ ditors' Note: Without Marshall Klaus and his proteges, Eleanor Molloy and Cynthia Bearer never would have met, and Pediatric Research would have a different editorial team!

Marshall H. Klaus, MD was born on 6 June 1927 in Cleveland, Ohio. He died on 15 August 2017 in California at age 90 years. He was educated in the Cleveland Public Schools system and then Case Western Reserve University, Cleveland, Ohio where he completed both his undergraduate and medical degrees. He thus fulfilled his childhood dream of becoming a physician like his father and uncle.

Marshall completed his Pediatric Internship and Residency at Babies and Children's Hospital (now Rainbow Babies \& Children's Hospital) in Cleveland serving, too, as the Chief Resident. During his residency, because of fears of infection, patient visitation was restricted to $30 \mathrm{~min}$ a week on a Saturday. He was influenced by lectures given by Anna Freud on hospitalization of children and visitation. When a ward was opened for unlimited visitation, he was impressed by the ability to render more effective patient care and improve family satisfaction Figure 1.

Following residency, he served in the US Air Force, then a 2-year stint in private practice in Northern California, which convinced him that he would rather focus on a research career. He then enrolled in a Pulmonary Medicine fellowship at the Cardiovascular Research Institute at The University of California in San Francisco and Oceanographic Institute in San Diego and completed in 1961.

Marshall rapidly emerged as a scientist and educator with big ideas and big plans. In academics, this traditionally required a team and, beginning in the 1960s, Marshall chose his teams well. His forays into Pulmonary Biology were mentored by giants in the field including John Clements, Richard Havel and Julius Comroe. He determined the composition of surfactant (1) and subsequently the origin of natural surfactant from alveolar epithelial cells (2). These studies formed a basis for Clements' development of an artificial surfactant and the highly successful introduction of surfactant into clinical therapy. Surfactant therapy remains a major component of the intensive care armamentarium.
Because he had a flail right arm as a consequence of polio contracted when he was a medical student, Marshall was always in favor of ventilatory support that did not require tracheal intubation, which was a daunting task for him. He was thus an early proponent of gentle ventilation and liberal use of continuous positive airway pressure. After a sabbatical in Europe, he returned with information from Italy on the use of nasal continuous positive airway pressure via nasopharyngeal tubes. He encouraged collaboration with the bioengineers and John Kattwinkel, a neonatal fellow working with Dave Fleming in Bioengineering, and designed the silicone nasal prongs that, with modification, are still effective and used today (3).

Marshall Klaus seemed destined for a career in pulmonary disorders. However, after observing aberrant behavior by the mothers whose babies had been ventilated, he switched direction to what is now termed "family centered care". For this endeavor, he wisely selected John Kennell as his professional partner in studying and establishing the importance of early mother/infant bonding. The combination of Marshall's novel thinking and unbridled enthusiasm was matched by John's calm demeanor and strong credentials as a giant in the broader world of Pediatrics. This probably contributed greatly to the dissemination of their remarkable scientific contribution to obstetric and neonatal practices. Together they systematically documented maternal/infant interactions, commencing in the first minutes of life (4). They made a compelling argument, based on good evidence, to allow fathers into the delivery room and encourage rooming-in with their mothers for healthy full-term infants. They paved the way to open the neonatal intensive care units for unlimited visitation and subsequently overnight visits for the parents. Their findings inspired labor wards and neonatal intensive care units to enable and encourage parents to enter the nursery to touch, hold, and care for their sick, malformed, and premature babies. They also established clinical guidance for provision of emotional support to parents, especially those dealing with the death of an infant.

The next chapter in his research focused on the impact of the "Doula", viz., a companion providing emotional support to the parturient. Together with his wife, Phyllis, and John

\footnotetext{
${ }^{1}$ Case Western Reserve University School of Medicine, Emeritus Eliza Henry Barnes Professor in Neonatology, Rainbow Babies \& Children's Hospital, Cleveland, Ohio; ${ }^{2}$ Pediatrics, Reproductive Biology, and Physiology \& Biophysics, Case Western Reserve University School of Medicine, Drusinsky/Fanaroff Professor in Neonatology, Rainbow Babies \& Children's Hospital, Cleveland, Ohio.

Correspondence: Avroy A. Fanaroff (aaf2@case.edu)

Received 6 September 2017; accepted 12 September 2017; advance online publication 15 November 2017. doi:10.1038/pr.2017.269
} 


\section{Commentary | Commentary}

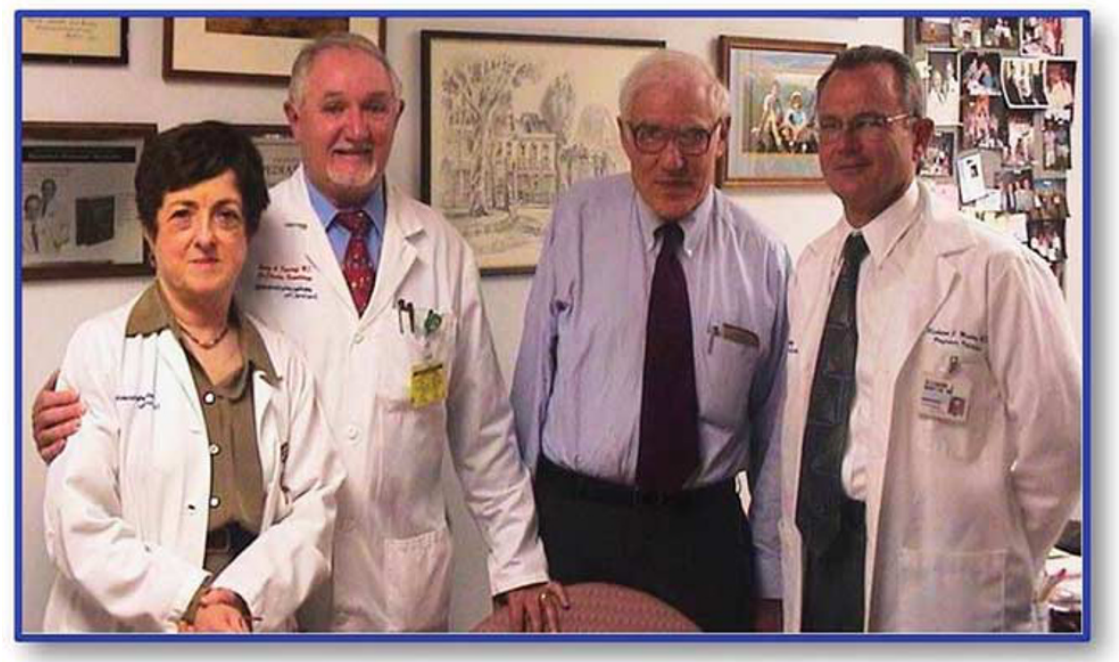

Figure 1. Klaus and his proteges.

Kennell, they were able to establish that with a doula present labor was shorter, discomfort was less, the need for Cesarean sections was less, and early attachment was promoted. This work launched a new profession, the "DOULA" (5). The concept of the doula is described in their collaborative work, The Doula Book (3rd edn, 2002) which, like all of his other books, has been translated into several languages.

Today, Marshall may be best remembered for the text Care of the High Risk Neonate, widely referred to as Klaus and Fanaroff, which made its debut in 1973 (6). Again, this was a reflection of Marshall's ability to recruit, then partner with me (AAF), and allow us to broaden our teaching credentials. This text evolved from dynamic regional seminars given by Marshall and me in Cleveland and surrounding areas in the late 1960s and early 1970 s to educate a whole spectrum of pediatricians and nurses on early neonatal care. The resultant text was a "first" in many respects. It was compact, yet packed with highly relevant facts, cases and commentaries. Most importantly, it was the first truly practical neonatal text and the key source of information for the generation of neonatologists trained in the 1970s and ensuing decades.

Marshall was a brilliant teacher and enthralling storyteller who captivated his audience. During rounds, he used play-acting as a potent teaching tool. This was very effective to illustrate how to break bad news such as the birth of a malformed infant, the death of a baby, and/or deterioration of a premature infant. $\mathrm{He}$ also directed and acted in "The Amazing Newborn"-a prizewinning movie-on the capabilities of the newborn (7).

Marshall was obsessed with finding a means of testing cortical/executive function in the newborn brain. He was fascinated that newly born infants mimicked adult gestures, such as tongue thrusting, and could move in rhythm to an adult's language (The Amazing Newborn). He believed that the ability to demonstrate visual preferences as reported by Fantz and Miranda (8) and subsequently used as an intelligence test was evidence of cortical function. These sophisticated tests, however, could not easily be generalized and applied at the bedside to all infants. A simple evaluation of cortical function remains elusive.

As a mentor, Marshall's contributions to the development of neonatologists of the 1970s were remarkable. He recruited and provided enormous support for his Rainbow Babies \& Children's Hospital fellows of that period, notably Howard Gruber, Roberto Sosa, Chul Choon Cha, John Kattwinkel, the late Maureen Hack, William Pittard, Waldemar Carlo and myself (RJM) to name a few. He always had great ideas for his trainees. Sometimes the results of these studies did not pan out as expected, but he could always put a positive spin on hard earned data generated by his trainees. His scientific rigor launched many careers and these individuals will always look back to Marshall with the utmost respect, fondness, and gratitude. We both are indebted to him for the solid academic foundation he built for us, together with the wisdom he offered throughout our careers.

In summary, Marshall was a family man, a wise man, and original thinker. He was warm and gregarious, loved his five children, and glowed when discussing his grandchildren. $\mathrm{He}$ was a kind and gentle man who loved spicy foods and orange peels. He was a man of vision, courage, conviction, passion, and compassion. As a pioneer in Neonatology, he broke grounds in two major areas-respiratory disorders and family centered care-together with establishing the value of a Doula during delivery. He influenced pediatricians and obstetricians to enable families to have a better birthing experience and a better experience in the neonatal intensive care units.

The words "Marshall Klaus" and "bonding" have become synonymous. Through his academic tree, his work will continue in perpetuity.

Avroy A. Fanaroff, MD.

Richard J. Martin, MD. 


\section{Commentary | Fanaroff and Martin}

Disclosure: The authors declare no conflict of interest.

\section{REFERENCES}

1. Klaus MH, Clements JA, Havel RJ. Composition of surface-active material isolated from beef lung. Proc Natl Acad Sci USA 1961;47:1858-9.

2. Bolande RP, Klaus MH. The morphologic demonstration of an alveolar lining layer and its relationship to pulmonary surfactant. Am J Pathol 1964;45:449-63.

3. Kattwinkel J, Fleming D, Cha CC, Fanaroff AA, Klaus MH. A device for administration of continuous positive airway pressure by the nasal route. Pediatrics 1973;52:131-4.
4. Klaus MH, Jerauld R, Kreger NC, McAlpine W, Steffa M, Kennel JH. Maternal attachment. Importance of the first post-partum days. N Engl J Med 1972;286:460-3.

5. Klaus MH, Kennell JH, Klaus PH. The Doula Book. Life Long Books. DaCapo Press: Philadelphia, USA, 1993.

6. Klaus MH, Fanaroff AA. Care of the High Risk Neonate. WB Saunders: Philadelphia, USA, 1973.

7. Hack M, Klaus MH. The Amazing Newborn. Polymorph Films, Boston, MA, USA, 1975.

8. Miranda SB, Hack M, Fantz RL, Fanaroff AA, Klaus MH. Neonatal pattern vision: a predictor of future mental performance? J Pediatr 1977;91:642-7. 